\title{
JOINT TEMPERATURE MEASUREMENT IN THE EVALUATION OF ANTI-ARTHRITIC AGENTS ${ }^{1,2}$
}

\author{
By JOSEPH L. HOLLANDER, EMERY K. STONER, ${ }^{3}$ ERNEST M. BROWN, JR., AND \\ PETER DEMOOR \\ (From the Arthritis Section, Department of Medicine, Hospital of the University of Pennsyl- \\ vania, Philadelphia, $P$ a.)
}

(Submitted for publication February 23, 1951; accepted April 10, 1951)

Accurate evaluation of the improvement in rheumatoid arthritis during therapy has always been greatly hampered by the lack of any quantitative criteria. Clinicians have depended upon a summation of clinical observation and a lowering of the erythrocyte sedimentation rate to prove a lessening of arthritic activity (1). Such clinical observations as decrease in joint tenderness or swelling, or increase in range of motion of the affected joints are subject to great variation of interpretation, depending upon the experience and enthusiasm of the physician, and upon the usual fluctuations of the disease process itself. The patient is often so enthusiastic about any new form of therapy that he minimizes his joint tenderness, and puts forth extra effort in attempting motion. The erythrocyte sedimentation rate, for years the only laboratory index of degree of activity in rheumatoid arthritis, is a non-specific test. Decrease in the rate often lags far behind obvious clinical improvement, and the degree of elevation of the sedimentation rate is not always in proportion to the activity of the arthritis (2). The ideal yardstick for improvement must be objective, must show changes promptly when they occur; the gradient must be sufficient to overshadow technical errors, and it must be consistent under standard conditions.

In previous reports, Hollander and Horvath $(3,4)$ have shown that the internal temperature of the rheumatoid arthritic joint appears to be elevated in close correlation with the amount of local inflammation as estimated from careful clinical evalu-

\footnotetext{
1 Read in part before the annual meeting of the American Rheumatism Association, San Francisco, California, June 23, 1950.

2 Aided in part by a grant from the United States Public Health Service.

3 National Foundation for Infantile Paralysis, Fellow in Physical Medicine.

4 Ayerst, McKenna and Harrison Fellow of the Association for the Study of Internal Secretions.

- Fellow of the Belgian-American Education Foundation.
}

ation. The internal temperature of a chronically inflamed joint varies little from day to day, or even from week to week, under standard conditions of rest and room temperature except when distinct changes in activity of the disease occur (4). Application of heat or cold over a joint, exercise $(4,5)$, and administration of certain drugs produce significant changes in joint temperature (6). Because of these observations, particularly the fact that intra-articular temperature determination apparently measures objectively the degree of inflammation of the rheumatoid arthritic joint, it was decided to study the effect of various anti-arthritic agents on the joint temperature in rheumatoid arthritis.

\section{METHODS}

As previously described (4), the method for determining intra-articular temperature consisted of inserting a filamentous copper-constantan thermocouple into the joint space (usually the knee) through the bore of an aspirating needle. In the experiments here reported, the e.m.f. developed was translated into degrees Centigrade by an automatic recording electronic potentiometer, which printed the temperature readings on a kymographic record. Determinations were made in a constant temperature room $\left(22^{\circ} \pm 1^{\circ}\right.$ C. $)$ with the patient at rest for 30 minutes.

At the time the aspirations for joint temperature determination were performed, specimens of the joint fluid were obtained for total leukocyte count. The synovial fluid specimens in oxalated tubes were examined within one half hour after collection. The fluid was diluted in a white cell pipette and counted in a standard counting chamber in the usual way. Tenth normal hydrochloric acid was used as the diluting fluid. Specimens which contained gross blood were not included.

Serial joint temperature determinations were made on 21 afebrile patients with active rheumatoid arthritis. In 19 of these an inflamed knee was studied, and in two the temperature in an inflamed ankle was measured. Control observations were made on two or three consecutive days prior to administration of cortisone acetate ${ }^{6}$ or

6 The cortisone acetate was supplied by Merck and Co. through Dr. James M. Carlisle, Medical Director, who also kindly supplied the tablets of cortisone used. 
pituitary adrenocorticotropic hormone (ACTH) 7 to be sure the pretreatment temperature was consistent. Eleven patients were observed with parenterally administered cortisone, and ten with ACTH. The dose of cortisone was $300 \mathrm{mg}$. the first day, and $100 \mathrm{mg}$. daily thereafter. ACTH was administered in $80 \mathrm{mg}$. daily doses $(20 \mathrm{mg}$. every six hours). Joint temperature determinations were made four hours after the first dose of drug in six instances, and daily determinations were made throughout the observation period in all.

In addition to the above studies, cortisone acetate tablets ${ }^{6}$ were administered orally to six patients with rheumatoid arthritis and serial joint temperature studies were performed. Control temperatures were taken just previous to administration and again after 48 and 96 hours of therapy. The oral dosage of cortisone was $150 \mathrm{mg}$. daily, administered as three doses of $50 \mathrm{mg}$. each for the first three days of the study period. The amount was then reduced to $100 \mathrm{mg}$. daily in divided doses. No other medication was used during the period of study in any case.

As an additional experiment eight patients with rheumatoid arthritis were given various agents, supposedly "anti-arthritic," for a period of one week in recommended "effective" doses. Following this, and without the patient's knowledge, $100 \mathrm{mg}$. daily of cortisone were sub-

7 The ACTH was supplied by Organon, Inc., through Dr. Kenneth Thompson, Medical Director, and by Armour Laboratories, through Dr. John R. Mote, Medical Director.

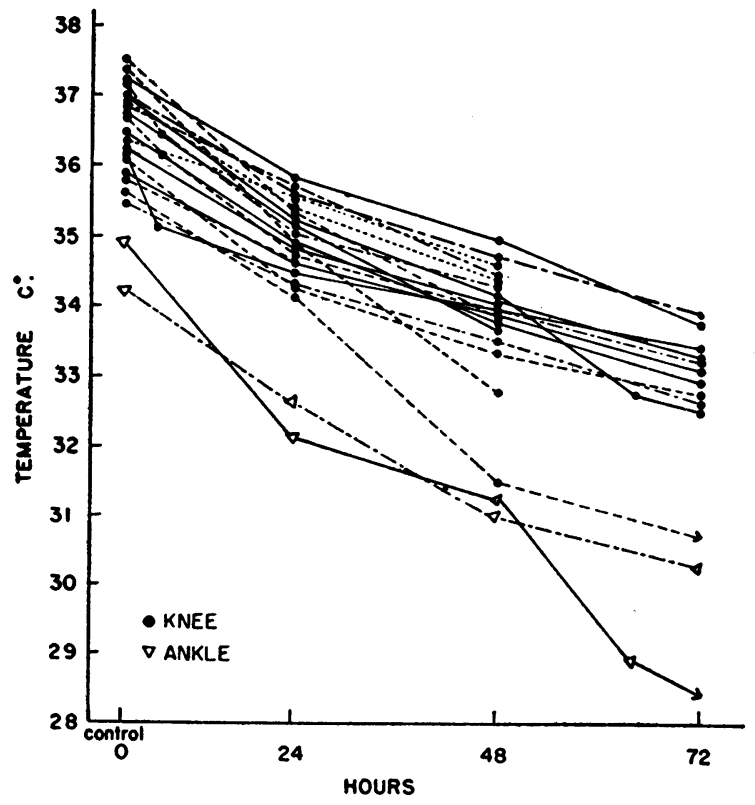

Fig. 1. The Initial Fall in Intra-articular Temperature in 21 Cases of Rheumatoid Arthritis on CORTISONE OR ACTH

Slopes in the ten on ACTH and the 11 on cortisone were so similar that they are not differentiated.

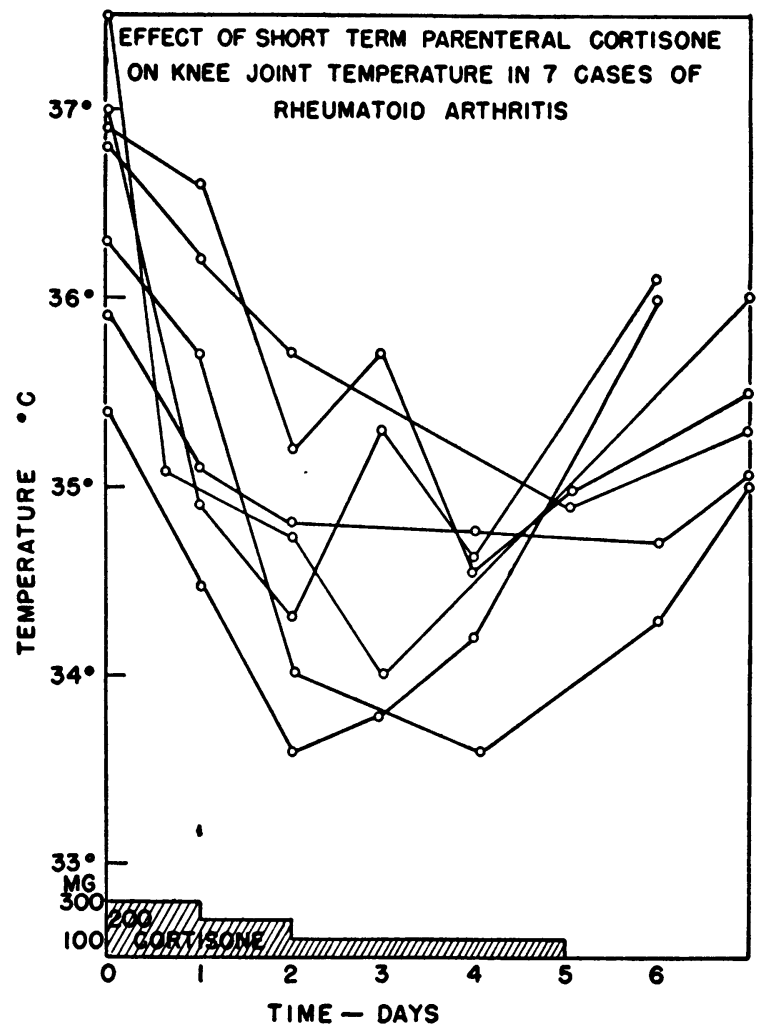

Fig. 2. Typical Variations in KneE Joint Temperature During and After Administration of CortiSONE (OR ACTH)

stituted for the unproved "anti-arthritic" agent being assayed. Daily joint temperature determinations were made throughout the experiment in each instance.

\section{RESULTS}

\section{Effect of Parenteral ACTH and Cortisone}

Within 24 hours of the initiation of hormone therapy, a prompt and consistent fall in joint temperature in every case was demonstrated. This initial trend is illustrated by Figure 1. The minimum decrease in joint temperature during the first 24 hours of administration of cortisone or ACTH was $0.7^{\circ} \mathrm{C}$., the maximum decrease was $2.7^{\circ}$, and the average was $1.4^{\circ} \mathrm{C}$. This is in contrast to a maximum fluctuation of $0.4^{\circ}$ during the control period. Since the rate of fall in both ACTH and cortisone treated cases was identical, they are not differentiated in the figure. On subsequent treatment days the joint temperature continued to decrease, usually approaching normal levels within three to five days (i.e., approximately $33^{\circ} \mathrm{C}$. for 
the knee, and $29^{\circ} \mathrm{C}$. for the ankle). A careful statistical analysis of the figures showed that the rate of fall was significant. ${ }^{8}$

It was observed that the fall in joint temperature on treatment with the hormones preceded detectable clinical improvement in 14 of the $21 \mathrm{pa}$ tients, and preceded by some days any significant change in the sedimentation rate in all but two instances. In five of the patients a rebound, or temporary increase in the joint temperature, was noted between the third and fifth day of treatment. Characteristic curves of the joint temperature response during and after cortisone administration are charted on Figure 2. These same variations were seen with ACTH.

The joint temperature began to rise within 24 to 48 hours after stopping ACTH or cortisone administration in all cases studied. This rise preceded clinical relapse in 17 instances. In five patients, however, some rise in temperature of the joint was noted even before the hormones were stopped. In 14 instances the joint temperature had returned to pre-treatment levels within one week after cessation of cortisone or $\mathrm{ACTH}$, but in seven cases (five ACTH treated, and two cortisone treated) the relapse to pre-treatment joint temperature levels was delayed until the ninth to 13th post-treatment day.

The serial synovial fluid cell counts on the patients during administration of cortisone or ACTH showed a pronounced decrease in leukocytes which paralleled the fall in joint temperature. This is illustrated in Figure 3. Frequent technical difficulties from clotting of the fluid, contamination with blood or insufficient fluid interfered with accurate results. Because of such difficulties only nine of the 21 cases under study could be charted.

\section{The Effect of Oral Cortisone on Intra-articular Temperature}

In all six patients to whom cortisone acetate was administered orally in the form of tablets, a marked drop in joint temperature was noted within 48 hours. Since these were out-patients, an initial 24 hour joint temperature determination was not accomplished. Figure 4 illustrates the drop in

8 Acknowledgment is made to Dr. J. Harold Austin, Emeritus Professor of Research Medicine, University of Pennsylvania, for the statistical analysis of the data.

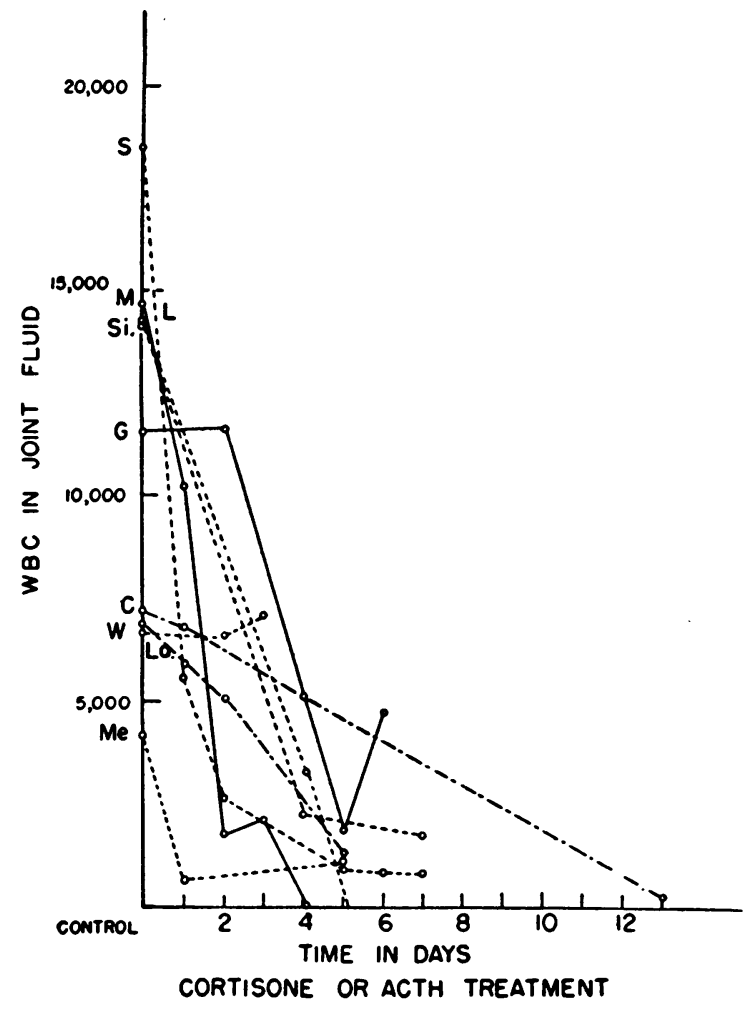

Fig. 3. The Effect of ACTH or Cortisone Administration on the Joint Fluid Cell Count in Nine Cases of Rheumatoid Arthritis

Cases S, M, C, and La were on ACTH; L, Si, G, W, and $\mathrm{Me}$ were on cortisone.

joint temperature after oral administration which paralleled the fall in joint temperature seen on parenteral administration (Figure 1). The clinical improvement noted in these patients was comparable to that seen with parenteral administration of cortisone.

\section{The Effect of Other So-called "Anti-arthritic" Agents versus Cortisone on Joint Temperature}

Since the method of joint temperature determination showed such a prompt change in every case treated with cortisone or ACTH, it has been used to test other possible "anti-arthritic" agents. Several steroids have been recommended for treating rheumatoid arthritis: delta-5-pregnenolone (7), testosterone (8), 21-acetoxypregnenolone (Artisone) (9), and others. Some of these were identified only by number as their structural formulae and chemical names had not been revealed at the time of study. The steroids used for the study 


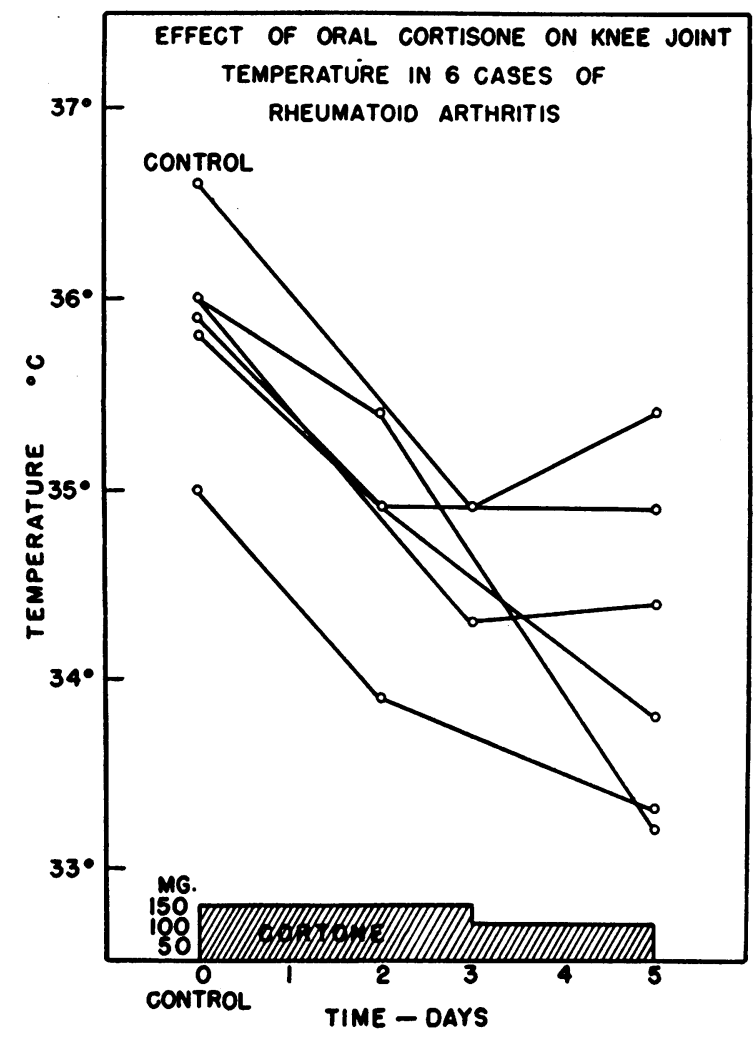

Fig. 4. The Initial Effect of Orally Administered Cortisone Acetate on KneE Joint Temperature in Six Cases of Rheumatoid Arthritis

were (a) No. 10270 (16-dehydropregnenolone acetate), (b) 21-acetoxypregnenolone (Artisone), $(c)$ testosterone propionate, $(d)$ delta-5 pregnenolone, and (e) C.S. 117 (21-acetoxypregnenolone acetate) ${ }^{9}$ In addition, one cinchoninic acid derivative (3-hydroxy, 2-phenyl cinchoninic acid), referred to as H.P.C., has been recommended for its possible anti-rheumatic activity (10). Because of the unproved effects of the "other steroids," as well as their unknown nature in some instances, they have been labelled in Figure 5 as "mysteroids." The doses of each agent used are given in the legend of Figure 5. Each one was administered in the "recommended" amounts, and continued for one week, after which cortisone was substituted in the usual dosage. Only one or two examples of treatment with each "mysteroid" were studied with serial joint temperature determination, as the clinical results in a series of patients treated

9 The above agents were kindly supplied by Eli Lilly and Co., Organon, Inc., and Wyeth, Inc. with each of these other agents had been discouraging. The contrasting effect, in each of the eight cases, of the unproved drug and cortisone on the joint temperature of the inflamed knee is apparent. These patients had been admitted "for cortisone treatment," so believed they were receiving cortisone from the beginning of the study. None of the "mysteroids" produced any significant fall in joint temperature nor objective clinical improvement, yet in every case a prompt and marked fall occurred with the administration of cortisone. The fall in joint temperature with the start of cortisone administration was accompanied by prompt clinical improvement in every case studied. Interestingly enough, without exception, these patients, even though unaware that cortisone had been substituted, remarked on this sudden change in effectiveness. The joint temperature in the patient given H.P.C. orally was depressed about $1^{\circ} \mathrm{C}$. from the control level throughout the

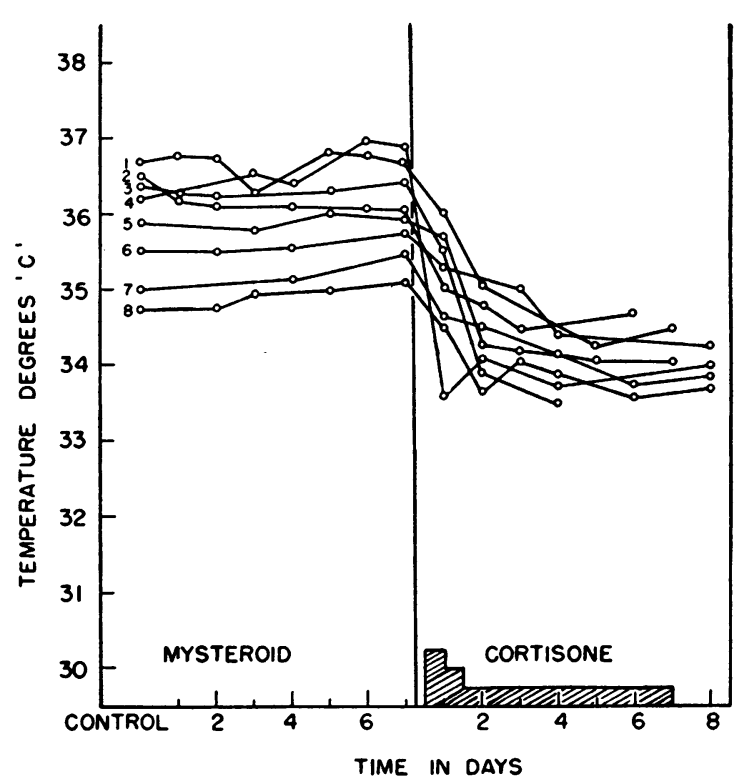

Fig. 5. The Comparative Effect of Administration of Other "Anti-Arthritic" Agents (Mysteroids) and Cortisone on the KNEE Joint Temperature in Eight Cases of Rheumatoid Arthritis

Cases 1 and 4 received $300 \mathrm{mg}$. daily of 16-dehydropregnenolone; cases 3 and 7 received $300 \mathrm{mg}$. daily of $21-$ acetoxypregnenolone; case 2 received orally $40 \mathrm{mg} . / \mathrm{kg}$. body weight daily of H.P.C.; case 5 received $200 \mathrm{mg}$. of testosterone propionate daily; case 6 received $300 \mathrm{mg}$. daily of delta-5 pregnenolone, and case 8 received 300 mg. of 21-acetoxypregnenolone acetate daily during the initial period. 


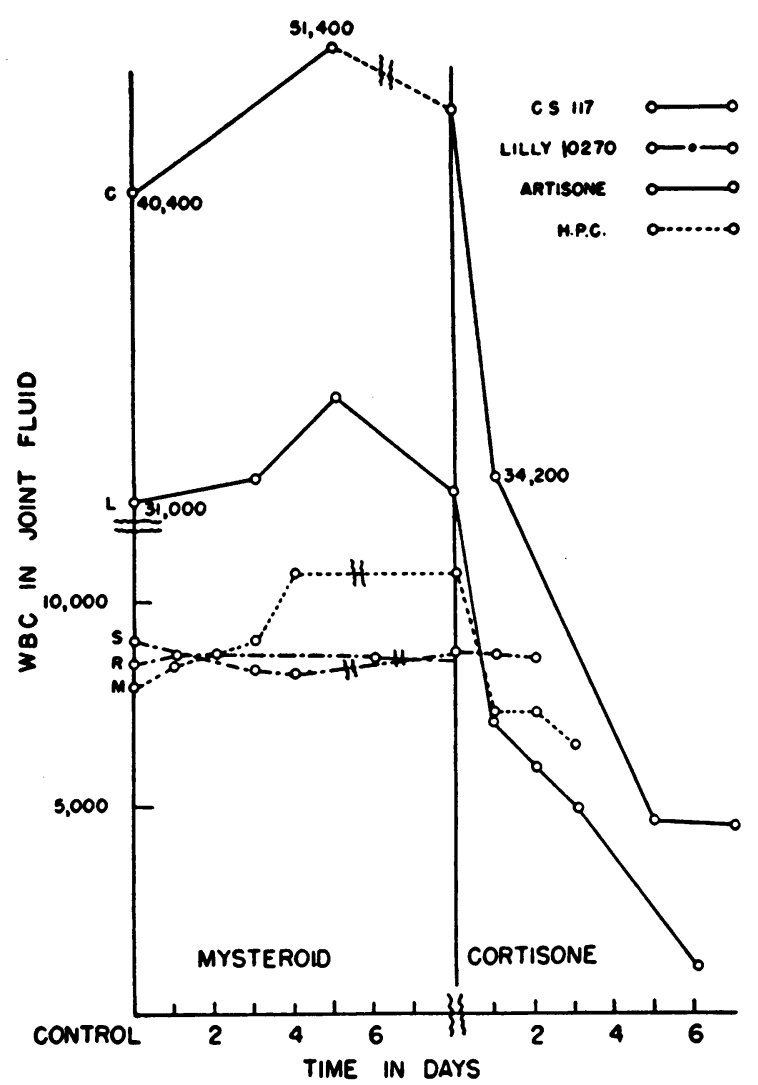

Fig. 6. The Comparative Effect of Administration of Other "Anti-arthritic" Agents and Cortisone on the Joint Fluid Cell Count in Four Cases of RheuMATOID ARThritis

Doses used were noted on Figure 5.

period of administration, much the same as previously noted from large doses of salicylates (6). Here again when cortisone was substituted the drop in joint temperature was more pronounced and objective clinical improvement was noted.

The correlated determination of cell count of the synovial fluid with this study is illustrated by Figure 6. Little change in the synovial fluid cell count was noted until cortisone was substituted for the "mysteroid," after which the cell count decreased in three out of four instances.

\section{DISCUSSION}

With the advent of cortisone and ACTH, it became possible to bring about rapid clinical improvement in rheumatoid arthritis. Using these agents, and correlating clinical improvement with joint temperature measurement, a distinct paral- lelism was demonstrated. The experiments were limited to relatively short periods of observation, but appeared to demonstrate the prompt effectiveness of the agents under study. Whereas clinical determination of effect is difficult to evaluate on any but a large series of patients over considerable time, serial joint temperature determination might provide a rapid, relatively simple criterion for determining drug effectiveness in active rheumatoid arthritis.

The changes in joint temperature produced by administration and withdrawal of ACTH and cortisone seem greater than one would expect from circulatory variation alone. Changes in tissue metabolism in the synovium might account for much of the increased or decreased heat. This is still under study.

Moderate variations of room temperature have only a relatively minor effect on joint temperature (4). The electronic potentiometer recorded room temperature as well as simultaneous skin and joint temperatures. It will be noted from Figure 3 that an occasional break in the steady downward slope of joint temperature was recorded. In three of five such instances a restless night preceded the test, but as yet no definite explanation for the temporary elevation has been found. Likewise, the rise in joint temperature seen before stopping the hormones in seven cases may have indicated that the dose was inadequate, but this is not certain.

At least by the criterion of joint temperature measurement no other drug has been found so far which has any therapeutic effect at all comparable to ACTH or cortisone. By this method also, the effectiveness of orally administered cortisone has been found comparable with the parenteral preparation.

Because of the already described technical difficulties experienced in performing the joint fluid cell counts, the method for determining clinical effect objectively by drop in cells in the synovial fluid was found to be inferior to the more consistent determination of joint temperature.

\section{SUMMARY}

Serial intra-articular temperature determinations were made on 21 rheumatoid arthritic patients before, during, and after a course of parenterally administered ACTH or cortisone. Cell counts were 
made on the synovial fluid obtained at the time of the aspirations for temperature determination in nine of the 21 patients. In every instance there was a pronounced fall in joint temperature within the first 24 hours of ACTH or cortisone administration, which approached normal by the fourth day of the treatment period. Joint fluid cell counts also showed a pronounced drop. Cortisone was administered orally to six patients with rheumatoid arthritis, with serial joint temperature determinations showing a similar fall in every instance. Eight patients with rheumatoid arthritis were given various other steroids for a period of one week, and serial joint temperature determinations made. Without the patients' knowledge cortisone was then substituted. None of these supposed anti-arthritic agents produced the fall in joint temperature which occurred in every case after the substitution of cortisone.

Serial joint temperature determination is suggested as a rapid and possibly specific laboratory method for establishing additional evidence of therapeutic effectiveness of anti-arthritic agents.

\section{ACKNOWLEDGMENTS}

Acknowledgement is made to Dr. Francis C. Wood, Professor of Medicine, and to Dr. Francis D. W. Lukens, Associate Professor of Medicine, University of Pennsylvania, for their assistance.

\section{REFERENCES}

1. Steinbrocker, O., Traeger, C. H., and Batterman, R. C., Therapeutic criteria in rheumatoid arthritis. J.A.M.A., 1949, 140, 659.
2. Coggeshall, $H$. C., The sedimentation rate, in Arthritis and Allied Conditions, Comroe, B. I. Lea \& Febiger, Philadelphia, 1949, 4th edition, pp. 55-62.

3. Hollander, J. L., and Horvath, S. M., Changes in joint temperature produced by diseases and by physical therapy; preliminary report. Arch. Phys. Med., 1949, 30, 437.

4. Horvath, S. M., and Hollander, J. L., Intra-articular temperature as measure of joint reaction. J. Clin. Invest., 1949, 28, 469.

5. Hollander, J. L., and Horvath, S. M., The influence of physical therapy procedures on the intra-articular temperature of normal and arthritic subjects. Am. J. M. Sc., 1949, 218, 543.

6. Hollander, J. L., and Horvath, S. M., The effect of vasodilating and vasoconstricting drugs on the temperature of joints and related structures, in Proc. of the Seventh International Rheumatism Congress (in press). Grune \& Stratton, New York. Also unpublished data.

7. Freeman, H., Pincus, G., Johnson, C. W., Bachrach, S., McCabe, G. E., and MacGilpin, H., Therapeutic efficacy of delta-5-pregnenolone in rheumatoid arthritis. J.A.M.A., 1950, 142, 1124.

8. Ishmael, W. K., Hellbaum, A., Kuhn, J. F., and Duffy, M., The effects of certain steroid compounds on various manifestations of rheumatoid arthritis; preliminary report. J. Oklahoma State M. A., 1949, 42, 434.

9. Seifter, J., Warter, P. J., and Fitch, D. R., Preliminary observations on the antiarthritic effect of 21-Acetoxypregnenolone, (in press). (Read before Easttern Pennsylvania Roundup, American College of Physicians, Philadelphia, January 20, 1950.)

10. Marshall, E. K., Jr., Harvey, A. M., Howard, J. E., Blanchard, K. E., Lubrod, C. G., Kattus, A., and Newman, E. V., The effect of 3-hydroxy-2-phenyl cinchoninic acid upon rheumatic fever. Tr. A. Am. Physicians, 1950, 63, 108. 